\title{
Automatic LPG gas Monitoring and Booking Through Android Application
}

\author{
S.Abirami, T.Priya, L.RohiniIswarya, M.Thaila, S.Priyanka
}

\begin{abstract}
Web of things assumes an essential job in this day and age. Web of Things points towards making life more straightforward via robotizing each little undertaking around us. As much as IOT helping in robotizing undertakings, the advantages of IOT can likewise be stretched out for improving the current security guidelines. Wellbeing, the rudimentary worry of any task, has not left immaculate by IOT. This framework will make a whole LPG chamber booking system computerized without human intercession. This is tied in with diminishing the condensed oil gas spillage and it consequently screens the dimension of gas in the chamber and we can see the gas use subtleties through android application in the event that the gas level achieves a base dimension, at that point naturally a message is sent to approved LPG specialist so they can convey LPG on schedule. Alongside the mechanized chamber booking we likewise structured component identified with the security of the client in which it persistently screens the spillage of LPG gas and cautions the client in regards to spillage through portable application by utilizing MQ5 gas sensor when it detects the spillage then quickly the fumes fan will be turned on naturally to maintain a strategic distance from real mishaps.
\end{abstract}

Keywords: Arduino Uno, MQ5 sensor, Load cell

\section{INTRODUCTION}

LPG first made in 1910. As LPG is adaptable in nature it is used for certain requirements, for instance, family fuel, present day fuel, customized fuel, warming, lighting up, etc. Various people are using LPG for cooking purposes. In most of our homes no safety efforts are taken against LPG chamber. This is an extraordinarily hazardous approach and it ought to be changed.

The gases being heavier than air don't dissipate adequately and when gas spills into the air may incite impact. Due to the spillage of LPG gases, the amount of passings has been extended recently. In India, the supply of LPG through pipelines is past the domain of creative ability as a result of absence of LPG. So advancement being improved various gas workplaces or wholesalers have executed IVRS these days yet in view of consistently involved timetables, customer discovers hard to book new barrel, and besides it is unsafe when a LPG gas spillage occurs in any family unit use and creation industry. This endeavor gives customized booking of LPG barrel and to overcome the LPG spillage issue.

Revised Manuscript Received on April 12, 2019.

S.Abirami, Department of Computer Science and Engineering, V.S.B Engineering College, Karur, Tamil Nadu, India. (abiramis84@gmail.com)

T.Priya, Department of Computer Science and Engineering, V.S.B Engineering College, Karur, Tamil Nadu, India.

L.RohiniIswarya, Department of Computer Science and Engineering, V.S.B Engineering College, Karur, Tamil Nadu, India.

M.Thaila, Department of Computer Science and Engineering, V.S.B Engineering College, Karur, Tamil Nadu, India.

S.Priyanka, Department of Computer Science and Engineering, V.S.B Engineering College, Karur, Tamil Nadu, India.
In this way, our recommendation is to absolutely motorize the methodology of refill booking without human intervention that properly will push purchaser to aware of gas usage. The fundamental objective of our undertaking is to measure the gas present in the barrel when weight of the chamber came to underneath the fixed weight at that point cautioning will be sent to the customer and methodologies customer for approval to book the chamber then The gas retailer gets the solicitation for another chamber and the house owner gets the message about the identical and the experiences concerning the booking strategies. The objective is to give any breakdown in gas system to turn away mischief or impact of LPG and another objective is if gas acknowledgment sensor MQ5 distinguishes a couple of gas spillage, by then it will normally slaughter the light it will trigger the alert, similarly as the vapor fan, will be swung on to clear the gas.

In the present system, LPG gas can be normally saved through GSM. It doesn't distinguish any spillage issues. We can't prepared to consider the step by step usage to LPG gas. In light of this present structure, there is a high chance to happen fire incident may happen. For that our thinking is to use a MQ5 gas sensor to recognize the gas spillage issue in homes. To screen the weight and consistently usage of gas using the store cell to measure.

\section{RELATED WORKS}

In all existing methods, different gas sensing technologies are used and LPG gas can be booked via SMS and IVRS. Most of the accidents happen due to not switch off the regulator properly. However, no control action is being taken. LPG gas comes in a metal cylinder and therefore, one cannot keep the track of the quantity of the consumption of the fuel. As a result sometimes in fact often it happens that one does not comes to know whether how much amount of fuel is remaining. So that booking for a new refill cylinder could be done before the gas in the container gets empty and the user gets deprived of the fuel till new refill is at doorstep.

\section{COMPONENTS USED}

Load cell is a sort of transducer which assumes the job of changing over power into an electric yield which can be estimated. Typically, the heaviness of a normal LPG chamber utilized for cooking is around $29.5 \mathrm{~kg}$ totally loaded up with gas and the heaviness of a vacant chamber is around $14.5 \mathrm{~kg}$. At the point when the heaviness of the

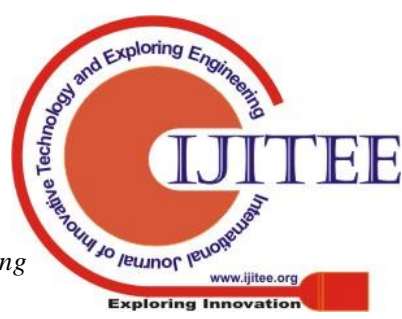


chamber falls beneath a specific dimension then this sensor will recognize the decreased weight and consequently gas booked utilizing the android application..

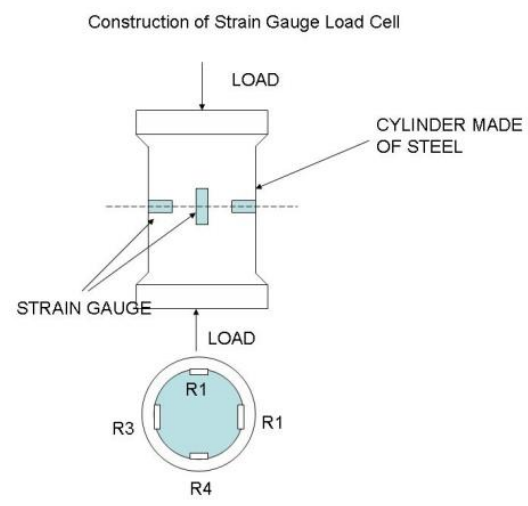

Gas Sensor (MQ5) module is useful for gas spillage revelation. It is sensible for recognizing $\mathrm{H} 2, \mathrm{LPG}, \mathrm{CH} 4, \mathrm{CO}$, Alcohol. On account of its high affectability estimations can be taken as fast as time licenses. The affectability of the MQ5 sensor can be adjusted by using the potentiometer. It can in like manner Wide distinguishing augmentation, stable long life, snappy response, and high affectability.

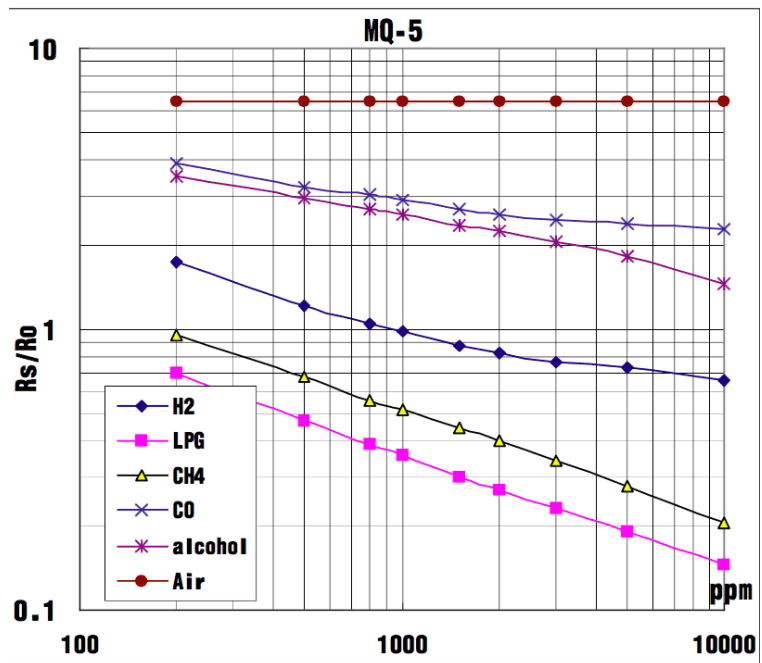

Arduino Uno is a microcontroller board made by Arduino.cc and reliant on Atmega328 and it has 14 propelled pins and 6 straightforward pins, 32KB of RAM memory. It is an open source organize where anyone can without a lot of a stretch change and improve the board reliant on the amount of rules and errand they have to achieve. This board goes with a verifiable rule feature which holds the voltage under the control when the device is related with the outside contraption. An Arduino is microcontroller motherboard. A microcontroller is a PC that can run one program at some random minute Arduino Uno would be the best, basic and most moderate decision. Arduino Uno Microcontroller is tweaked using an Arduino Integrated Environment or rather Arduino Software [IDE]. This IDE helps recorded as a printed copy a direction code for the Arduino.

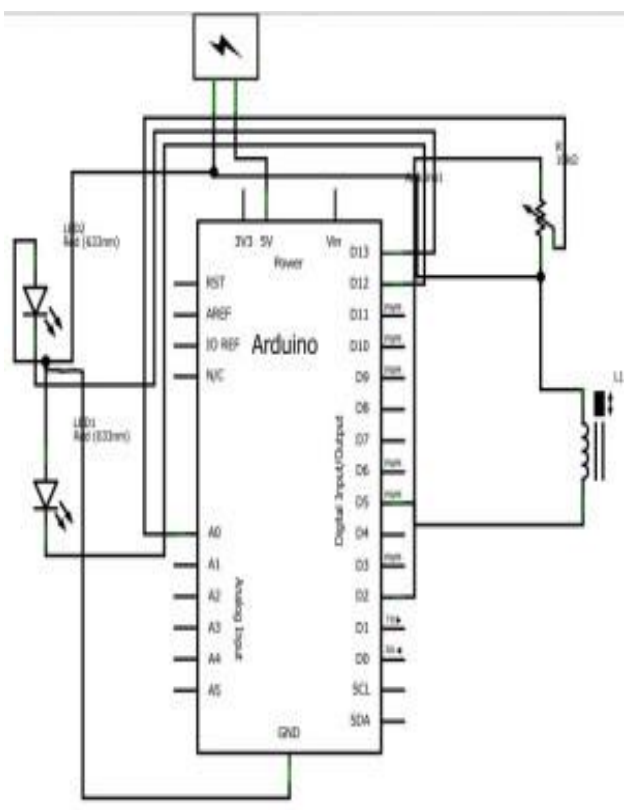

ESP8266 12E The ESP8266 WiFi Module is an autonomous SOC with joined TCP/IP show stack that can give any microcontroller access to your WiFi compose. It is changing the world no sweat and high features which makes it an ideal module for Internet Of Things (IOT). It might be used in any application where you need to interface a device to your close-by framework or web. This is definitely not hard to use and strong subject to ESP8266 chipset to be used nearby a microcontroller that structures and bestows through AT bearings. A robotized LPG system can help the purchasers in overcoming the various issues and can be an alternative as opposed to the current IVRS LPG booking structure. In this structure, the client needs to dial a toll free or without non number to select a booking organization. For this circumstance, there are high shots where the purchaser may disregard to book for his next cycle. So to avoid this barrel booking is done through a message sending process by the structure when the largeness of the chamber is at its point of confinement. Edge can be set by client at the same time system will sent caution message to trader association.

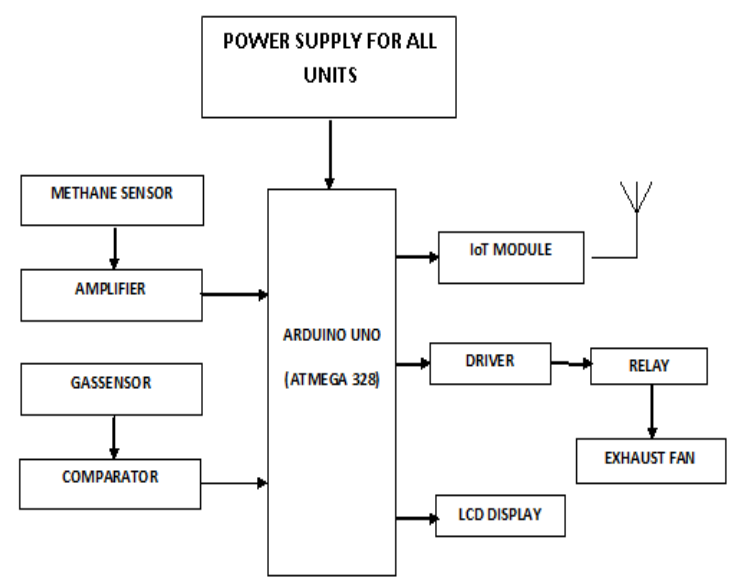




\section{PROPOSED SYSTEM}

In existing frameworks there are numerous issues some might be commonly individuals sees that in our home at whatever point LPG gas barrel is vacant, at that point we give ask for new chamber at the workplace of LPG gas supplier. Commonly it happens that there is delay in giving gas barrel. Primary explanation for this is delay in booking or illuminating to the gas supplier. The utilization of the LPG gas is in the home or eatery for the cooking reason and it likewise valuable in ventures for the cutting or welding reason. LPG gas comes in metal chamber and in this way one can't monitor the amount of the utilization of the fuel. It doesn't recognize any spillage issues. We can't ready to think about the everyday utilization to LPG gas. Because of this current framework there are high opportunities to happen fire mishap.

In our proposed framework by utilizing the android application client can think about the weight and utilization of here burden cell to compute the heaviness of the barrel. Assuming any spillage happens then promptly ready message will be informed by means of utilization.

- Automatic LPG cylinder booking

- Gas leakage detection

In this framework we constantly measure the measure of gas present in the chamber utilizing load cell which is interfaced with Arduino Uno. Client can see the day by day utilization of gas level through the android application. At the point when gas level goes beneath the set dimension at that point message will be sent to the gas office and notice about same is given to the client utilizing web. In this way, client get chamber inside time. In gas spillage recognition process, any gas spillage is checked by gas sensor (MQ5) which is interfaced with Arduino Uno. At the point when spillage is distinguished by sensor at that point promptly fumes fan will be turned on and in the meantime it educate the client about the gas spillage by sending the alarm messages.

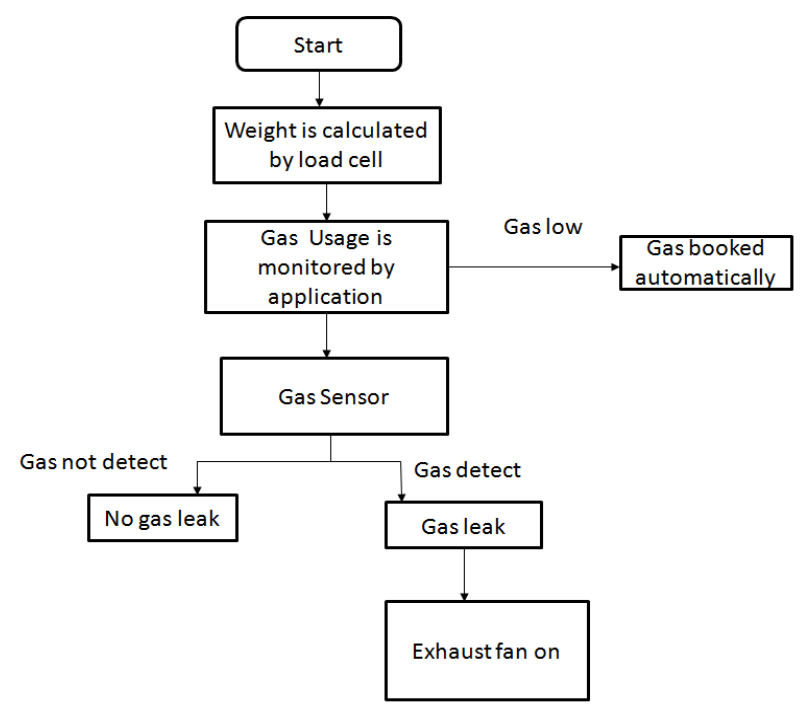

\section{EXPERIMENT AND RESULT ANALYSIS}

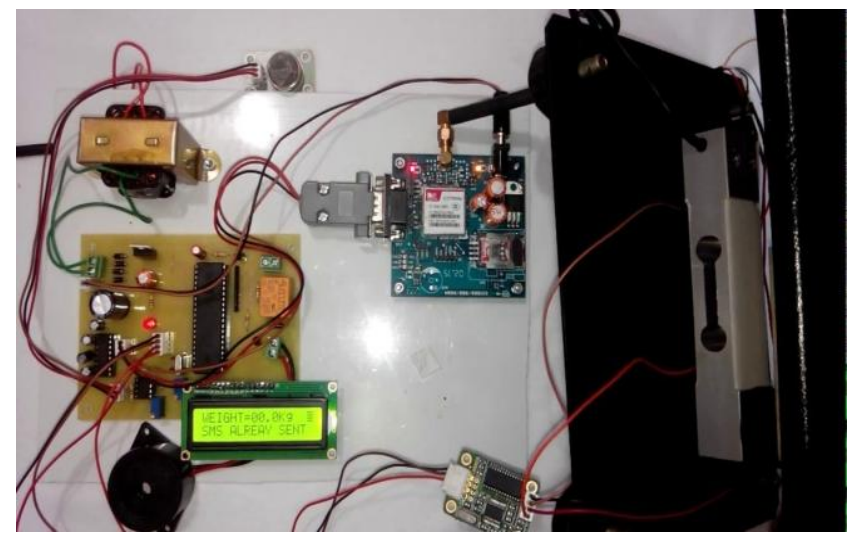

Weight of the chamber is estimated by utilizing load cell it is coordinated with arduinouno ESP8266 12E is IOT module to control the gadgets all segments are associated with arduniouno. Gas level is shown in LCD and we can ready to see it in android application. On the off chance that any release happens, at that point gas sensor detects spill and send an alarm message to the LPG gas client at that point fumes fan will be turned on promptly to keep away from significant mishaps.

- Message is displayed on LCD to alert the users and nearby people.

- SMS/e-mail send via internet using the cloud to the users.

- exhaust fan will fan out all enclosed gas from the environment. When reset button of MCU pressed the system will get refreshed.

Alongside accomplishment of these proposed highlights effectively, one of the central point of cost proficiency or standardization has likewise been the worry all through which is additionally acquired concentration amid the way toward building this framework.

\section{CONCLUSION}

This venture is created and tried as for real parameters of LPG. For example, discovery of LPG spillage and execution of security against gas spill. Consequently turn on the fumes fan to discharge the gas and screens the day by day use of gas by android application then programmed booking of chamber is done when it will exhaust.

\section{FUTURE SCOPE}

Future degree of IOT is high and its use is rapidly extending in future IOT will expect a key occupation in controlling everything by using the sensors. By organizing Arduino with android application customer can get each day reviving. Here we have used the IOT advancement to make a gas spillage locator for society which having Smart Alerting methods including sending text to the concerned master by using sensor. This structure will in all likelihood perceive the gas in condition using the gas sensors. This will deflect structure the major destructive setback 


\section{REFERENCE}

1. Aastha Singh, Mr. Manish Verma, Mr. LumeshSahu "Detection of Liquefied petroleum gas using sensor through arduinouno microcontroller" International Research Journal of Engineering and Technology.

2. Shraddha Suresh Tanksale, Prof. A.S. Mali and Dr.B.T.Salokhe "Automated Unified Trolley System for LPG Leakage Detection with Safety Measures and Refill Booking International Journal of Engineerig and Management Research.

3. Vinayak V. Mane, ShreyasS.Madhekar, AnandS.Kulkarni, Prof. Vishal Katekar " Gas Leakage Detection with Automatic Booking \& Valve Bypass" International Research Journal of Engineering and Technology (IRJET).

4. Ravindra R. Hiwase, Priya K. Kewate, Sushmita P. Tajane, JitendraWaghmare "Automatic LPG Cylinder Booking and Leakage Detection using Arduino UNO" IJESC.

5. Shital Imade, Priyanka Rajmane,AishwaryaGavali,V.N.Nayak wadi "Gas leakage detection and smart alerting system using iot" International Journal of Innovative Research \& Studies.

6. Alan Macker Anil Kumar ShuklaSagarikaDeyJyotiAgarwal "ARDUINO Based LPG gas Monitoring \&Automatic Cylinder booking with Alert System" International Conference on in Electronics and Informatics (ICOEI 2018).

7. AkibIslam"Android Application Based Smart Home Automation System using Internet of Things" International Conference for Convergence in Technology (I2CT)

8. AdeosunOlajideOlusegun, Olajide Blessing Olajide" Design and Construction of a Domestic Microcontroller based Dangerous Gas Detector" International Journal of Scientific Research and Management (IJSRM)

9. Bowles, J.B. An Assessment of RPN Prioritization in a Failure Modes Effects and Criticality Analysis. In Proc. of the IEEE Annual Reliability and Maintainability Symposium, Tampa, EUA, pp 380-386, 2003.

10. Ryan, M. Supply Chain Asia - Technology. Available in: http:// supplychainasia.org/you-can-t improve what -you-cant-see/ Access date: 01/11/2015. 2015.

11. Nizam, C.K. et al. Radio Frequency Identification (RFID): Airbus Business Radar. AIRBUS, 2015.

12. Roberti, M. Airbus Enters New Phase of RFID Usage, Digitalization. RFID Journal, 2015.

13. IDTechEx, The RFID: Knowledgebase Sample Case Studies. Cambridge, UK. 2015.

14. ANP - AgenciaNacional do Petroleo. Relatório de Analise de ImpactoRegulatorio (AIR) - Requalificaçao de RecipientesTransportaveis de AçoparaGásLiquefeito de Petróleo (GLP). Rio de Janeiro. fevereiro 2015.

15. Moreira, M.F. Uso de RFID naGestao de ArtigosRetornaveisemCadeias de DistribuiçaoTipo ClosedLoop. Dissertaçao de Mestrado - PUC Rio. 2013.

16. X. Liu et al., "A survey on gas sensing technology," Sensors, vol. 12, no. 7, pp. 9635-9665, July 2012.

17. R. Chen et al., "Optimizing design for polymer fiber optic oxygen sensors," IEEE Sensors Journal, vol. 14, no. 10, pp. 3358-3364, October 2014.

18. W. R. O. for Europe, WHO Guidelines for Indoor Air Quality: Selected Pollutants. World Health Organization, November 2011.

19. N. B. Hampson, "Cost of accidental carbon monoxide poisoning: A preventable expense," Preventive Medicine Reports, vol. 3, pp. 21-24, June 2016.

20. M. U. H. Al Rasyid, I. U. Nadhori, and Y. T. Alnovinda, "CO and $\mathrm{CO} 2$ pollution monitoring based on wireless sensor network," in 2015 IEEE International Conference on Aerospace Electronics and Remote Sensing Technology (ICARES), Bali, Indonesia, 3-5 December 2015. 